\title{
Japon akçaağaç odununun bazı fiziksel ve mekanik özelliklerinin belirlenmesi üzerine bir çalışma
}

\author{
Fatih Tuncay Efe $(D)$
}

\section{$\ddot{\mathbf{O} z}$}

Japon akçaağacı (Acer Palmatum) dünya genelinde yayılış gösterir. Ancak çoğu Japonya kökenli olup, Kore ve Çin'de de yayılış gösterir. Japon akçaağacı 15 m'ye kadar büyüyebilir. Çoklu gövdesi güçlü görüntüye sahiptir. Akçaağaç odunu, mobilya, paneller, parke, kereste, LVL (Lamine Kaplama Kereste), Glulam (Yapıştırılmış Lamine Ahşap), müzik enstrümanları, alet sapları, dipçik, ahşap kiriş, uçak pervanesi, ahşap köprü, vb. gibi çeşitli alanlarda kullanılır. Mekanik özellikler bilhassa binalarda kullanılan yap1 elemanları için en önemli karakteristiklerdir. Herhangi bir kullanış yeri için malzeme seçiminde bu özelliklerin bilinmesi büyük önem taşımaktadır. Japon akçaağacı odununun yoğunluk, eğilme direnci, elastikiyet modülü, şok direnci ve vida tutma direnci bu ağaç odununu kullanan veya kullanacak işletmelere teknik bilgi sağlamak için araştırılmıştır. Hava kurusu yoğunluk, eğilme direnci, elastikiyet modülü, şok direnci ve vida tutma kapasitesi (Teğet, radyal ve enine yönde) sırasıyla; $574 \mathrm{~kg} / \mathrm{m}^{3}, 78 \mathrm{~N} / \mathrm{mm}^{2}, 6808 \mathrm{~N} / \mathrm{mm}^{2}, 0.217 \mathrm{kgm} / \mathrm{cm}^{2}$ ve $\left(35.1 \mathrm{~N} / \mathrm{mm}^{2}, 33.1 \mathrm{~N} / \mathrm{mm}^{2}\right.$ ve 28.9 $\mathrm{N} / \mathrm{mm}^{2}$ ) olarak tespit edilmiştir. Sonuçlar Japon akçaağacı odununun diğer akçaağaç türlerine göre daha düşük yoğunluğa, düşük eğilme ve şok direncine sahip ve gevrek bir yapıda olduğunu göstermiştir.

Anahtar kelimeler: Japon akçaağaç odunu, eğilme direnci, şok direnci, vida tutma direnci

\section{A study on the determination of some physical and mechanical properties of Japanese maple wood}

\begin{abstract}
Japanese maple (Acer Palmatum) spreads worldwide. However, most of them originate from Japan and also spread in Korea and China. Japanese maple can grow up to $15 \mathrm{~m}$. Its multibody has a powerful appearance. Maple wood is used in various fields such as furniture, panels, parquet, lumber, LVL (Laminated Veneer Lumber), Glulam (Glued Laminated Timber), musical instruments, instrument handles, stock, wooden beam, airplane propeller, wooden bridge, etc. Mechanical properties are the most important characteristics especially for building elements used in buildings. It is of great importance to know these properties in the selection of materials for any use place. The density, bending strength, modulus of elasticity, impact strength and screw holding resistance of Japanese maple wood were investigated to provide technical data for users. Air dry density, bending strength, modulus of elasticity, impact strength and screw holding capacity (in tangent, radial, and transverse directions) were respectively; 574 $\mathrm{kg} / \mathrm{m}^{3}, 78 \mathrm{~N} / \mathrm{mm}^{2}, 6808 \mathrm{~N} / \mathrm{mm}^{2}, 0.217 \mathrm{kgm} / \mathrm{cm}^{2}$ and $\left(35.1 \mathrm{~N} / \mathrm{mm}^{2}, 33.1 \mathrm{~N} / \mathrm{mm}^{2}\right.$ and 28.9 $\mathrm{N} / \mathrm{mm}^{2}$ ). The results showed that Japanese maple wood has a low density value, low bending strength and impact strength, and a brittle structure compared to other maple species.
\end{abstract}

Keywords: Japanese maple wood, modulus od rupture, modulus of elasticity, screw holding strength

Makale tarihçesi: Geliș:07.12.2020, Kabul: 19.12.2020, Yayınlanma: 28.12.2020, *e-posta: fatihtuncayefe@ gmail.com *Çanakkale Onsekiz Mart Üniversitesi, Yenice Meslek Yüksekokulu, Ormancılık Bölümü, Çanakkale/Türkiye Atıf: Efe F.T., (2020), Japon akçaağaç odununun bazı fiziksel ve mekanik özelliklerinin belirlenmesi üzerine bir çalışma, Mobilya ve Ahşap Malzeme Araştırmaları Dergisi, 3 (2), 110-118, DOI: 10.33725/mamad.837309 


\section{Giriş}

Bazı kaynaklara göre Türkiye'de doğal olarak yetişen 9 akçaağaç türü, Kayın gövdeli akçaağaç (Acer trautvetteri), Beşparmak akçaağaç (Acer cappadocicum), Çınar yapraklı akçaağaç (Acer platanoides), Ova akçaağacı (Acer campestre), Beşloplu akçaağaç (Acer divergens) (Acer quinquelobium). Fransız akçaağacı (Acer monspessulanum), Doğu akçaağacı (Acer sempervirens), Toros akçaağacı (Acer hyrcanum) ve Tatar akçaağacı (Acer tataricum) (Bozkurt ve Erdin, 2011); bazı kaynaklara göre ise akçaağacın 12 türü, Dicle Akçaağacı (Acer assyriacum Pojark.), Ova Akçaağacı (Acer campestre L.), Beş parmak Akçaağac1, (Acer cappadocicum Gleditsch), Balkan Akçaağacı (Acer heldreichi Orph. ex Boiss), Mey Taraklık Akçaağacı (Acer hyrcanum Fich..\& C.A.), Fransız Akçaağacı (Acer monspessulanum L.), Şark Akçaağacı (Acer obbusifolium Sm.), Çınar Akçaağacı (Acer platanoides L.), Dağ Akçaağacı (Acer pseudoplatanus L.), Keleve (Acer sempervirens L.), Tatar Akçaağacı (Acer tataricum L.), İsfendan (Acer negundo L.) (Öztürk, 2019).

Ormanlarımızda genellikle diğer ağaç türleri ile karışık olarak bulunmakta ve genellikle Kuzey, Doğu ve Güney Anadolu'da yayılış göstermektedir. Hammadde olarak daha çok Karadeniz ormanlarından temin edilmektedir. Akçaağaçlarda genellikle belirgin koyu renkli bir öz odun yoktur. Odunu diri odun özelliğinde olup çoğunlukla kremsi beyaz ile pembemsi beyaz renktedir. Özel bir koku ya da tada sahip değildir. Düzgün lifli olup, bazen dalgalı liflilik veya kuşgözü oluşumları görülebilir. Akçaağaç türlerinin hava kurusu yoğunluğu $0,55-0.80 \mathrm{~g} / \mathrm{cm}^{3}$ arasında değişmektedir. Odunu sert, güç eğilir, şok direnci yüksek ve çalışması fazladır. Dermatitise neden olabilir (Bozkurt ve Erdin, 2011). Ülkemizde bitkisel tasarım çalışmalarında, Acer palmatum Thunb., Acer palmatum "Atropurpurea", Acer palmatum "Dissectum", Acer platanoides L, Acer platanoides "Crimson King" ve Acer saccarinum L. en çok kullanılan akçaağaç taksonları olarak dikkati çekmektedir. Fakat bu taksonların hiçbiri ülkemizde doğal olarak yetişmemekte ve ithal edilerek peyzaj tasarımlarında kullanılmaktadır (Öner ve ark., 2014).

Acer Palmatum, genel olarak Japon akçaağacı olarak bilinir ve dünya genelinde yayılmış yüzlerce çeşidi vardır (Brand 2015). Bu çeşitlerin çoğu Japonya kökenlidir ancak Kore ve Çin'de de yayılış gösterir. Japon akçaağacı 15 m'ye kadar büyüyebilir. Çoklu gövdesi güçlü görüntüye sahiptir. Yeşil veya kırmızı yaprakları vardır (Gilman, 1999). Akçaağaç, mobilya, paneller, parke, kereste, LVL, Glulam, müzik enstrümanları, alet sapları, dipçik, ahşap kiriş, uçak pervanesi, ahşap köprü, vb. gibi çeşitli alanlarda kullanılır (Korkut ve Büyüksarı, 2006).

Mekanik özellikler bilhassa binalarda kullanılan yapı elemanları için en önemli karakteristiklerdir. Herhangi bir kullanış yeri için malzeme seçiminde bu özelliklerin belirlenmesi önem arz etmektedir. Örneğin; ağaç malzemenin binalarda taşıyıcı, döşeme kirişi, çatı kerestesi veya kontrplak çatı örtüleri, lamine kirişler, merdiven ya da telekomünikasyon direkleri, tel direkleri, yat direkleri ve mobilya iskeleti gibi kullanım yerlerinde mekanik özelliklerin bilinmesi gerekir (Bozkurt ve Erdin, 2011). Bu bilgiler, ağaç malzemenin taşıyıcı, destekleyici veya sadece dekorasyon amaçlı kullanılıp kullanılmayacağı konusunda yol gösterici olacaktır.

Önceki çalışmalarda genel olarak akçaağacın elastikiyet modülü $9400 \mathrm{~N} / \mathrm{mm}^{2}$, eğilme direnci 95 N/mm² (Bozkurt ve Erdin, 2011; As vd., 2001); Çınar yapraklı akçaağaç (Acer platanodies L.) için eğilme direncini $137 \mathrm{~N} / \mathrm{mm}^{2}$, hava kurusu yoğunluğu $660 \mathrm{~kg} / \mathrm{m}^{3}$, Dağ akçaağacı (Acer pseudoplatanus L.) için eğilme direncini $112 \mathrm{~N} / \mathrm{mm}^{2}$, hava kurusu yoğunluğu $630 \mathrm{~kg} / \mathrm{m}^{3}$; Ova akçaağacı (Acer campestre L.) için hava kurusu yoğunluğu $730 \mathrm{~kg} / \mathrm{m}^{3}$ olarak tespit edilmiştir (As vd., 2001). Erten ve Sözen (1994), Çınar yapraklı akçaağaç (Acer platanodies L.) için hava kurusu yoğunluğu $640 \mathrm{~kg} / \mathrm{m}^{3}$ belirlemişlerdir. Bozkurt ve Erdin 
(2013), akçaağacın eğilme direncini $93 \mathrm{~N} / \mathrm{mm}^{2}$, elastikiyet modülünü $9200 \mathrm{~N} / \mathrm{mm}^{2}$ olarak bulmuşlardır. Diğer taraftan Kayın gövdeli akçaağaç odununun (Acer trautvetteri Medw.) tam kuru özgül ağırlığı 591.76 kg/m³ (Ayata vd., 2019); hava kurusu özgül ağırlığ1 $638.13 \mathrm{~kg} / \mathrm{m}^{3}$, vida tutma direnci teğet yüzeyde $39.91 \mathrm{~N} / \mathrm{mm}^{2}$, radyal yüzeyde $36.63 \mathrm{~N} / \mathrm{mm}^{2}$ ve enine yüzeyde $33.45 \mathrm{~N} / \mathrm{mm}^{2}$ olarak ölçülmüştür (Çavuş ve Ayata, 2018).

Literatür taramasında Japon akçaağacı odununun fiziksel ve mekanik özelliklerine dair herhangi bir çalışmaya rastlanmamış olup; bu çalışma ile bu konudaki eksikliğin giderilmesi ve elde edilen tespitlerden bu ağaç odununu ticari olarak kullanan ve kullanacak işletmelere bilgi sağlanması amaçlanmıştır.

\section{Materyal ve Metot}

\subsection{Materyal}

Çalışmada kullanılan Japon akçaağacı (Acer Palmatum) İzmir'deki bir kereste tüccarından tomruk biçiminde alınarak latalara biçildi, 4 ay açık hava şartlarında kurutuldu ve deney numuneleri bu latalardan kesilerek elde edildi.

\subsection{Metot}

Test örnekleri, $20 \pm 3{ }^{\circ} \mathrm{C}$ sıcaklıkta ve $\% 65 \pm 5$ bağıl nem şartlarında 2 ay bekletilmiştir. Test örneklerinin hava kurusu yoğunluk değerleri $\left(\mathrm{D}_{12}\right)$ TS 2472 'de belirtilen esaslara göre. Test örneklerinin eğilme direnci TS 2474'e, eğilmede elastikiyet modülü TS 2478'e, şok (dinamik eğilme direnci) direnci TS 2477'ye göre hesaplanmıştır. Vida tutma direnci TS EN 13446 numaralı standartta belirtilen esaslara uygun olarak yapılmıştır.

Mekanik testlere ait görüntüler Şekil 1-A, 1-B ve 1-C'de ve test örneklerinin görüntüsü ise Şekil 1-D'de verilmiştir. Eğilme direnci test örnekleri 2x2x36 cm ölçülerinde, şok direnci

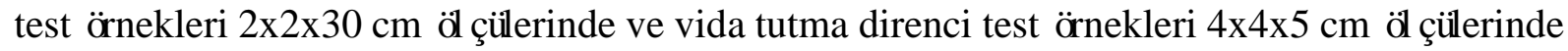
hazırlanmıştır (Şekil 1-D). Vida tutma direncinde ön delik çap1 $2.5 \mathrm{~mm}$, vida çap1 $4 \mathrm{~mm}$, vida boyu $50 \mathrm{~mm}$ ve vida girme derinliği $20 \mathrm{~mm}$ olarak alınmıştır. Eğilme direncinde mesnetler arası mesafe $30 \mathrm{~cm}$ ve şok direncinde $24 \mathrm{~cm}$ olarak ayarlanmıştır. Eğilme direnci ve şok direnci testinde kuvvet radyal yüzeye uygulanmıştır. Tüm testlerde 15 'er adet örnek kullanılmıştır.

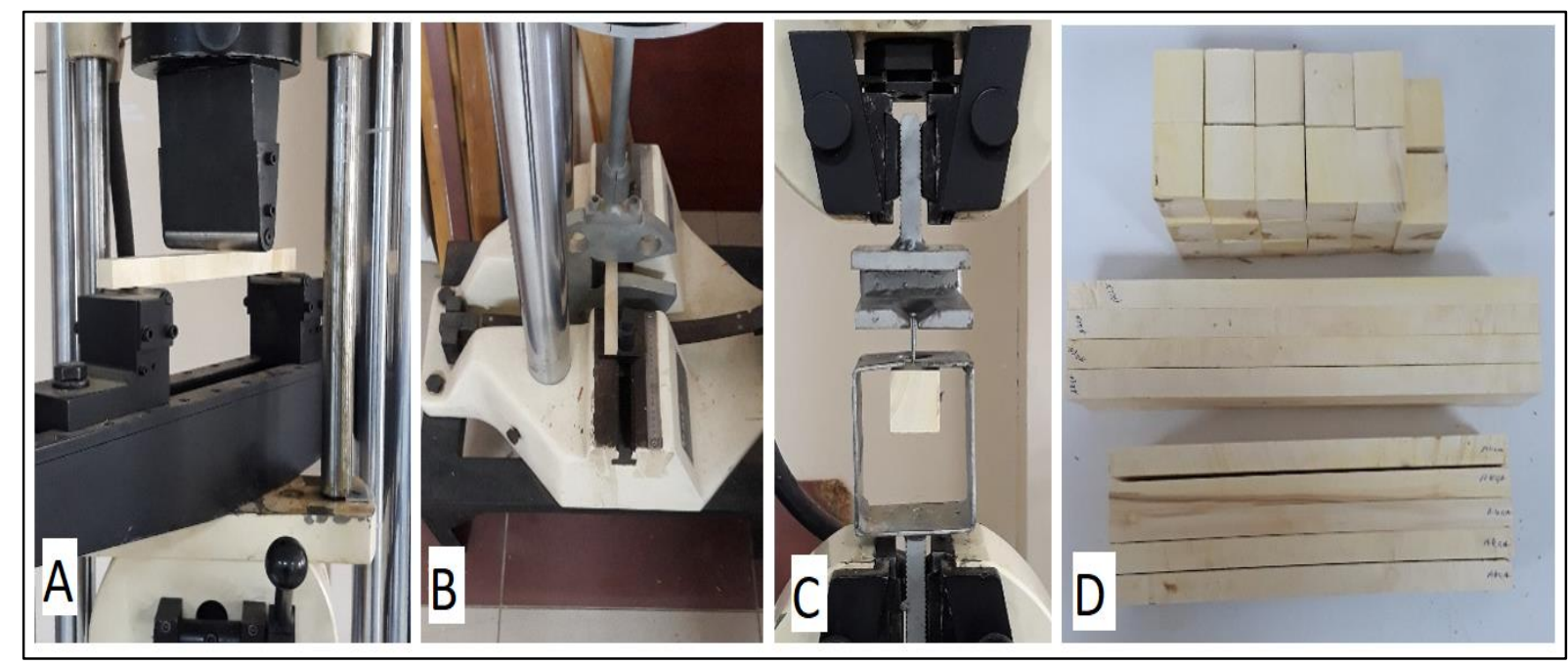

Şekil 1. A: Eğilme direnci, B: şok direnci, C: vida tutma direnci, D: test örnekleri 


\section{Bulgular ve Tartışma}

Tablo 1, Japon akçaağacı odununun bazı fiziksel ve mekanik test sonuçlarını göstermektedir. Çalışmada elde edilen hava kurusu yoğunluk ortalama $574 \mathrm{~kg} / \mathrm{m}^{3}$, eğilme direnci ortalama $78 \mathrm{~N} / \mathrm{mm}^{2}$ ve elastikiyet modülü $6808 \mathrm{~N} / \mathrm{mm}^{2}$ olup; Bozkurt ve Erdin (2011)'in tespitleriyle uyumlu ancak As vd. (2001), Erten ve Sözen (1994) ve Çavuş ve Ayata (2018)'in tespitlerinden daha düşüktür. Bunun nedeni ağaç türü veya örneklerin tomruktan alındığı kısım farklılığı olabileceği söylenebilir. Bu verilere göre Japon akçaağacı (Acer Palmatum) odunu için genel olarak literatürde tespit edilen diğer akçaağaç türlerinden daha hafif, eğilme direnci ve dinamik eğilme direnci daha düşük, dolayısıyla daha gevrektir denilebilir.

Akçaağaçlar yoğunluklarına göre iki gruba ayrılmıştır. Birinci gruptakilerin yoğunluğu $580 \mathrm{~kg} / \mathrm{m}^{3}-660 \mathrm{~kg} / \mathrm{m}^{3}$ arasında, ikinci gruptakilerin yoğunluğu ise $660 \mathrm{~kg} / \mathrm{m}^{3}-800 \mathrm{~kg} / \mathrm{m}^{3}$ arasındadır (Yaltırık, 1971a; 1971b). Bu sınıflandırmaya göre Japon akçaağacı birinci gruba daha yakındir.

Dinamik eğilme (Şok) direnci ortalama $0.217 \mathrm{kgm} / \mathrm{cm}^{2}$, vida tutma direnci değerleri teğet, radyal ve enine yüzeylerde $35.1 \mathrm{~N} / \mathrm{mm}^{2}, 33.1 \mathrm{~N} / \mathrm{mm} 2$ ve $28.9 \mathrm{~N} / \mathrm{mm}^{2}$ olarak ölçüldü. Çalışma konusu Japon akçaağacı odununun vida tutma direnci değerleri Çavuş ve Ayata (2018)'nın buldukları değerlere (teğet yüzeyde $39.91 \mathrm{~N} / \mathrm{mm}^{2}$, radyal yüzeyde $36.63 \mathrm{~N} / \mathrm{mm}^{2}$ ve enine yüzeyde 33.45 $\mathrm{N} / \mathrm{mm}^{2}$ ) göre daha düşük; ancak yüzeylere göre elde edilen verilerin mantıksal siralanması bakımından (En yüksek teğet yüzeyde, en düşük enine yüzeyde) uyumludur.

Odun hücrelerinin gövde eksenine paralel dizilişi, yıllık halkaların her bir yüzeydeki farklı konumu bu durumu etkilemektedir. Teğet yüzeyde y1llık halkalar üst üste binmiş mikro tabakalar olduğu için vidanın bu yüzeyde tutunması daha güçlü; enine yüzeyde ise vidanın yıllık halkalara paralel bir tutunması söz konusu olduğu için tutunma daha zayıftır.

Tablo 1. Japon akçaağacı odununun fiziksel ve mekanik test verileri

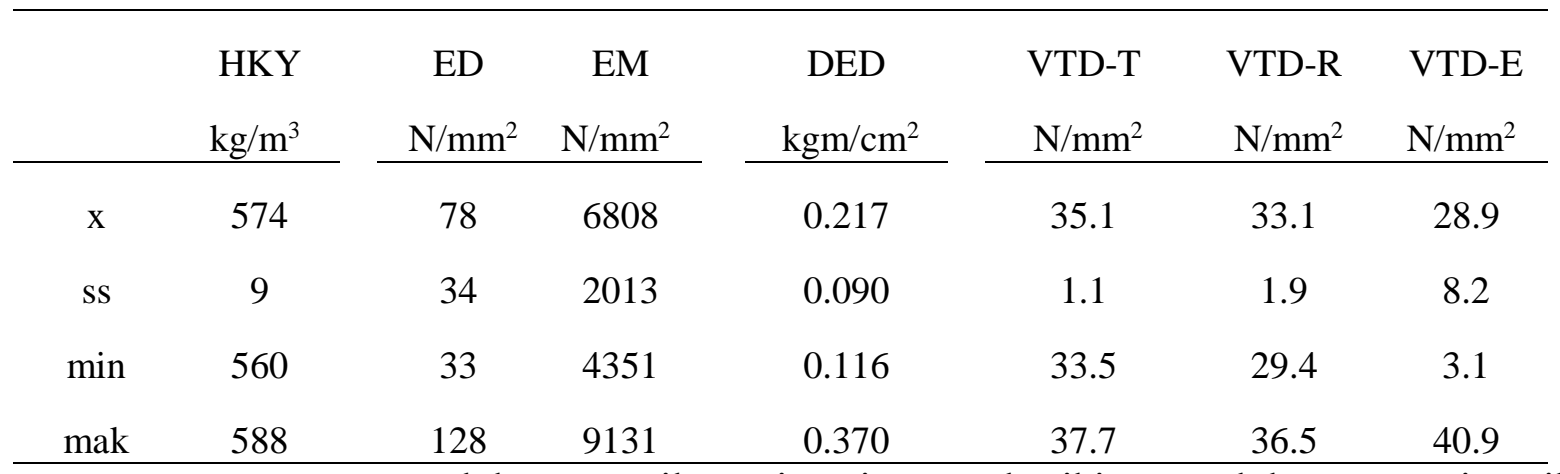

HKY: Hava Kurusu Yoğunluk, ED: Eğilme Direnci, EM: Elastikiyet Modülü, DED: Dinamik Eğilme Direnci, VTD-T/R/E: Teğet/Radya1/Enine yüzeylerde Vida Tutma Direnci.

Bir malzemenin sertliği, uygulanan kuvvete karşı gösterdiği direnci yansıtır ve elastik bölgenin eğiminden saptanır. Şekil 2'ye göre yük-deformasyon eğrisinin altında kalan alan malzemenin kırılıncaya kadar depoladığı enerji (work to failure; U) olarak tanımlanır ve malzemenin kırılganlığı hakkında bilgi verir. Maksimum deformasyon (ultimate displacement) malzemenin kırılma anına kadar yapıda oluşan deformasyon miktarıdır ve malzemenin kırılabilirliği (brittleness) ile ilişkilidir. Maksimum kırılma kuvveti (ultimate load veya ultimate force) malzemenin kırılma anında gözlenen kuvvet değeridir ve malzemenin yapısal açıdan genel bütünlüğünü yansıtır. Yük-deformasyon eğrisinden elastik sınır bölgesi, maksimum kırılma kuvveti ve maksimum deformasyon direkt olarak ölçülebilir. Sertlik ve depolanan enerji ise yük-deformasyon eğrisinden hesaplanır (Gürgül vd., 2016). 

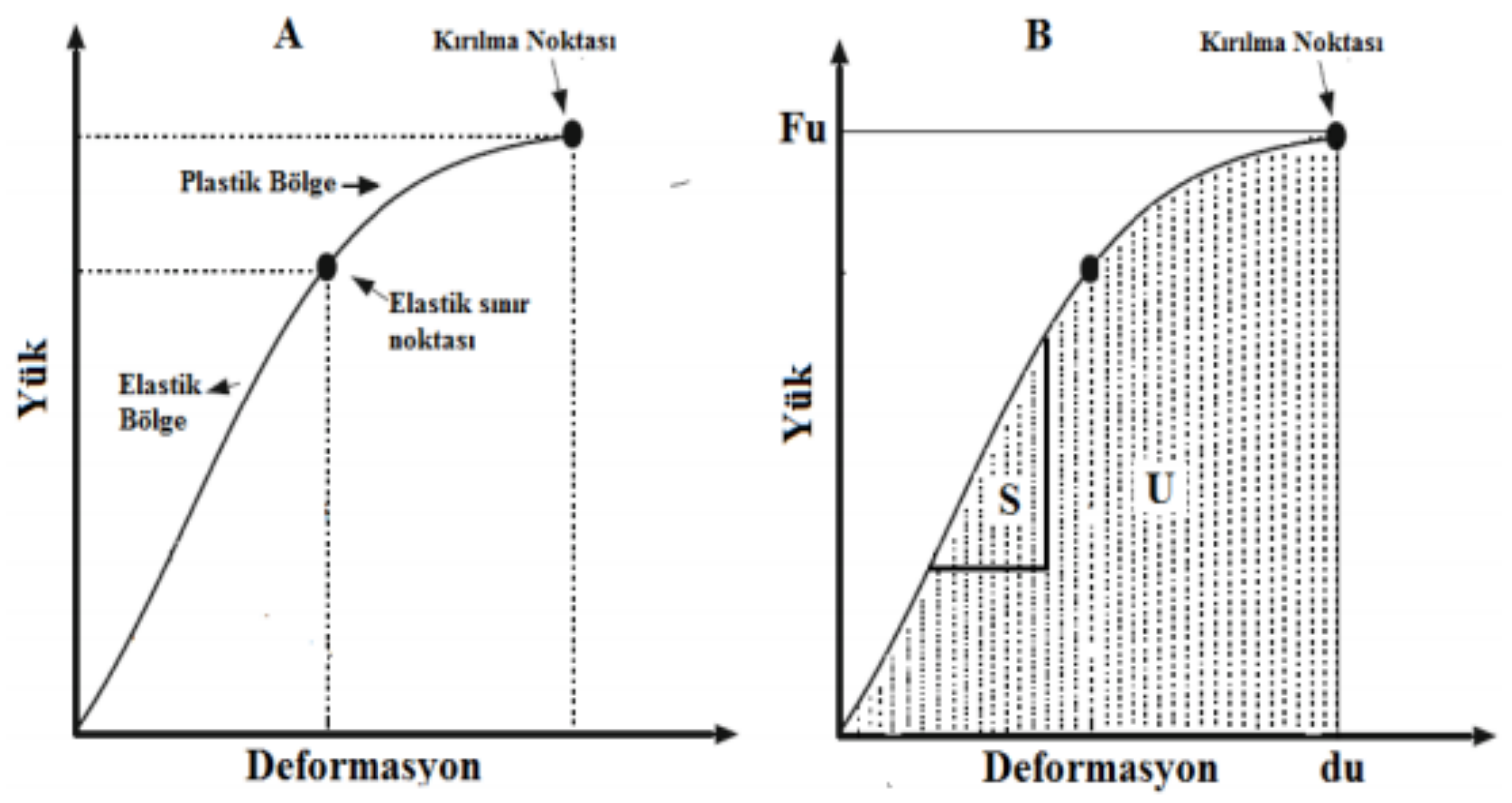

Şekil 2. A: Yük-deformasyon eğrisi ve bu eğrinin bölümleri. B: Yük-deformasyon eğrisi ve bu eğriden saptanan yapısal mekanik parametreler S: Sertlik, U: Depolanan enerji, Fu: Maksimum kırılma kuvveti, du: Maksimum deformasyon.

Şekil 3'te enine yüzeyde yapılan vida tutma direnci testi esnasında elde edilen yükdeformasyon grafiği verilmiştir. Grafik incelendiğinde elastik bölge sınırının bazı istisnalar hariç $2.4 \mathrm{~mm}$ olduğu ve örnekten örneğe değişkenlik gösterdiği ve örneklerin elastiklik sınırından sonra plastik davranmadan deforme oldukları anlaşılmaktadır. Çoğu örnekte deformasyonun $3.6 \mathrm{~mm}$ sınırına kadar gerçekleştiği görülmektedir. Hemen hemen tüm test örneklerinin (15 nolu örnek hariç) en fazla $3.8 \mathrm{~mm}$ 'lik bir deformasyon sonunda testin sonlandığı görülmektedir. Örneklerin çoğunun deformasyona uğradığı aralık 2.4 mm-3.6 mm olarak tespit edilmiştir.

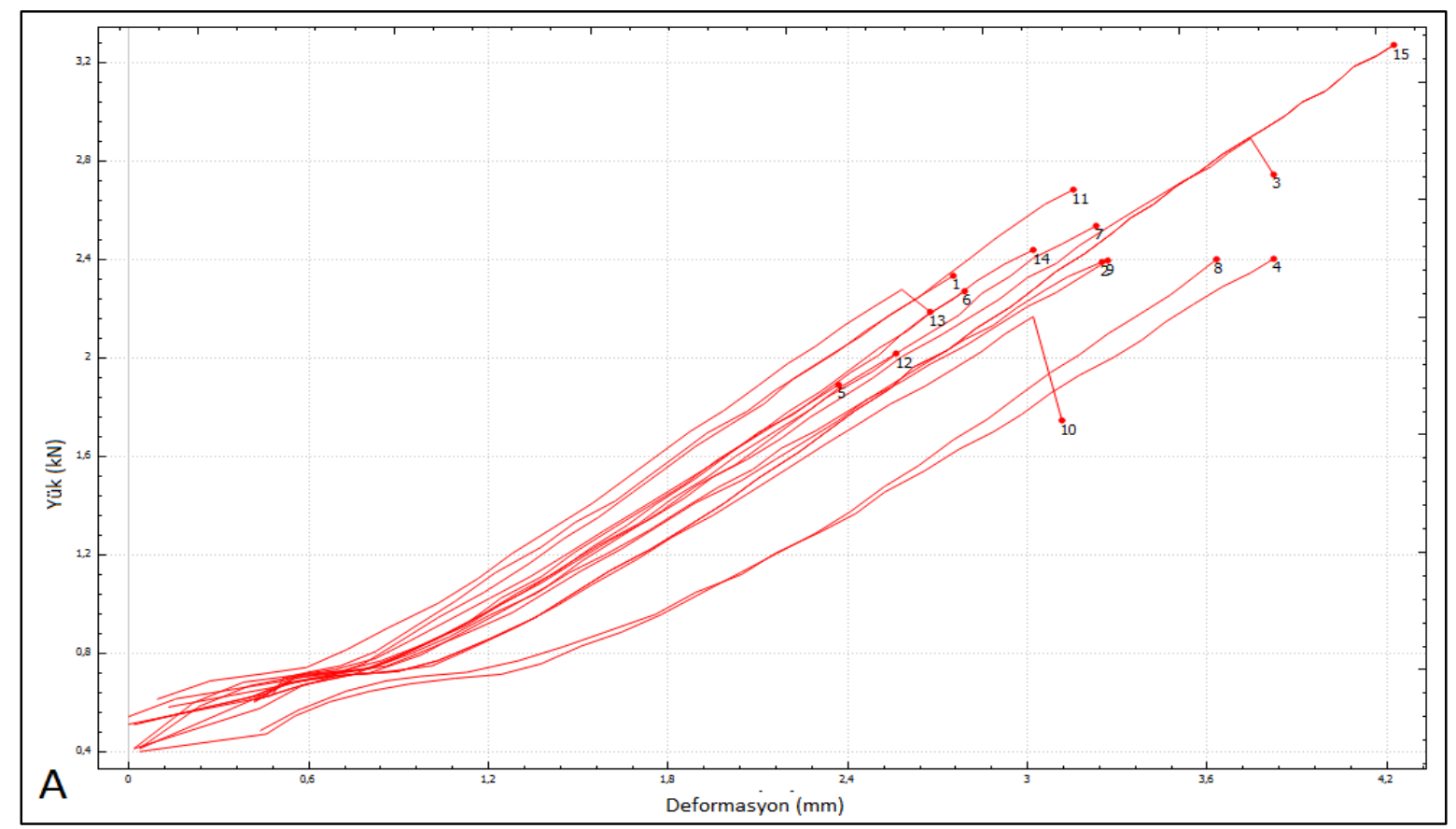

Şekil 3. Enine yüzeyde yapılan vida tutma direnci testine ait yük-deformasyon grafiği 
Şekil 4'teki grafiğe göre radyal yüzeye uygulanan vida tutma testindeki yük-deformasyon değişimi enine yüzeydekinden oldukça farklı gerçekleşmiştir. Örneklerin yaklaşık 3.2 mm'ye kadar elastik davranış gösterdiği; $3.2 \mathrm{~mm}-3.84 \mathrm{~mm}$ arasında plastik davrandığı ve bu noktadan itibaren deformasyonun başladığ görülmüştür.

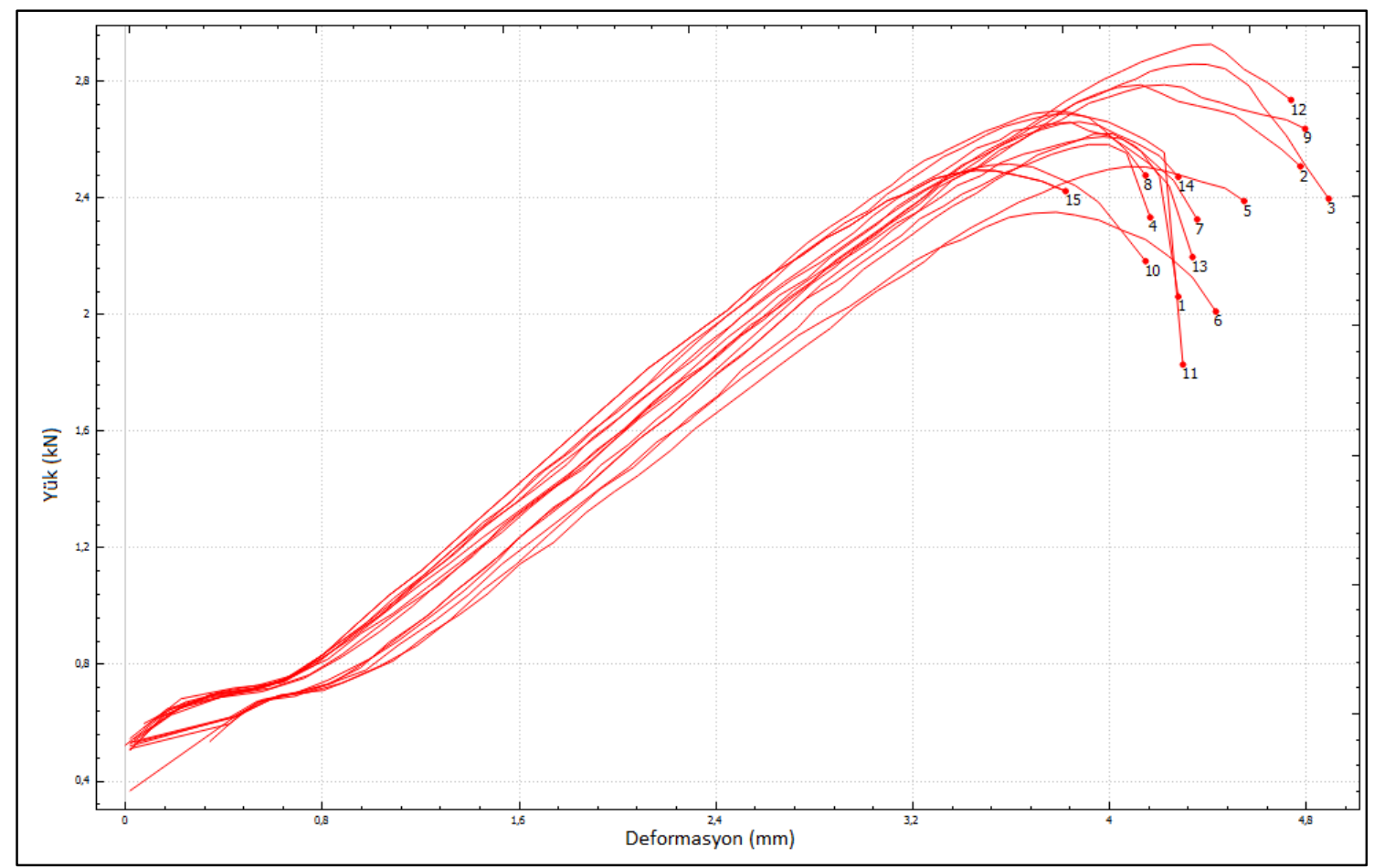

Şekil 4. Teğet yüzeyde yapılan vida tutma direnci testine ait yük-deformasyon grafiği

Şekil 5'te örneklerin dinamik eğilme (Şok) direnci testi sonrası durumu görülmektedir. Örneklerin kırılma bölgeleri incelendiğinde genelde kıymıksız olduğu görülmektedir. Birkaç örneğin dışında uzun kıymık oluşumu gözlenmemiştir. Şok direnci testi sonrası test örneklerinin kırılma noktalarında meydana gelen kıymıklı veya kıymıksız kırılma şekilleri, test edilen masif ağaç malzemenin tokluk özelliğini göstermektedir. TS 2477'ye göre kırılma noktasında 3 mm'den daha uzun kıymık oluşması, malzemenin sünek özellik gösterdiğini; kıymık boyu $3 \mathrm{~mm}$ 'den daha kısa olan kırılma şekilleri ise gevrek malzemeyi işaret etmektedir. İlgili standarda göre, bu çalışmada denemeleri yapılan akçaağaç odunu gevrek özellik göstermektedir denebilir. Ağaç malzemenin gevrek veya sünek yapıda olması onun kullanım amaçlarını etkilemektedir. Özellikle ahşap konstrüksiyona sahip yapılar, köprüler ve çatıların yük taşıyan kiriş, kolon gibi kısımlarında gevrek malzemenin kullanımı sakıncalı olabilir. Benzer bilgiler, farklı odun türlerinin şok direnci üzerine yapılan çalışmalarda da rapor edilmiştir (Bektaş, 1997; Bektaş ve ark., 2002; Bal, 2011; Bal ve ark., 2012; Bal ve Bektaş, 2018; Çavuş, 2020). 


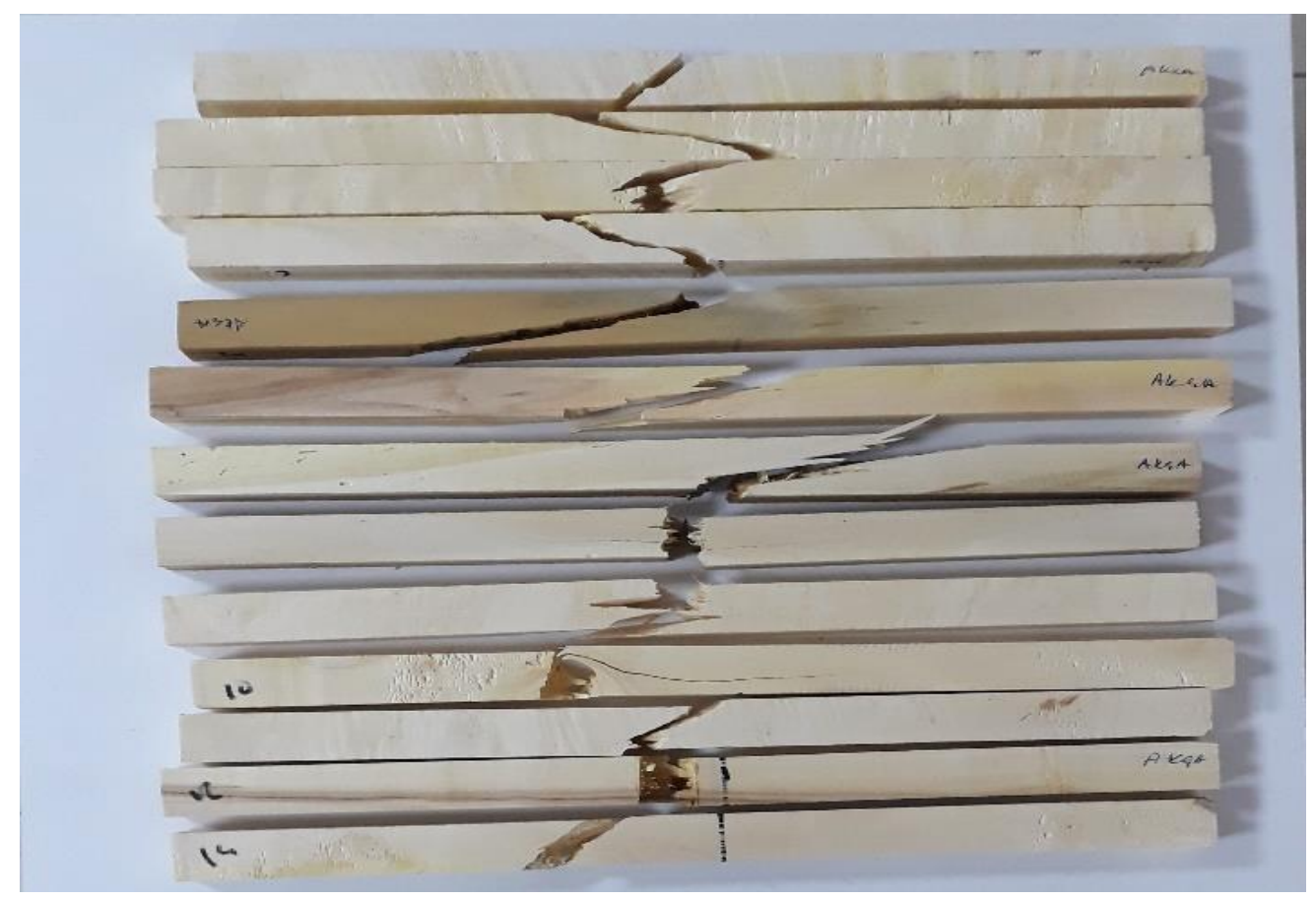

Şekil 5. Şok direnci test örnekleri test sonrası görüntüsü

\section{Sonuçlar ve Öneriler}

$\mathrm{Bu}$ çalışmada, Japon akçaağacı odununun bazı fiziksel ve mekanik özellikleri araştırılmıştır. Elde edilen verilere göre şu sonuçlar söylenebilir;

- Japon akçaağacı odunu, yoğunluk bakımından literatürdeki diğer akçaağaç türleri odunlarına göre daha düşük yoğunluk değerine sahiptir.

- Japon akçaağacı odununun eğilme direnci, elastikiyet modülü ve dinamik eğilme (Şok) direnci değerleri literatürdeki diğer akçaağaç türü odunlarınınkine göre daha düşük; dolayısıyla onlardan daha gevrek ve mekanik özellikler bakımından dayanıksız bir yapıdadır.

- Vida tutma direnci değeri, en düşük enine yüzeyde ve en yüksek teğet yüzeyde elde edilmiştir.

- Bulgular, Japon akçaağacı odununun orman ürünleri sektöründe özellikle statik yük taşıyan ve/veya çarpmaya maruz kalan ahşap yapı elemanı olarak kullanılmasında dikkatli olunması gerektiğini göstermektedir. Bahsedilen kullanım alanlarında, yüksek dayanım gerektiren uygulamalarda Japon akçaağacı tercih edilmeden önce çalışmada tespit edilen verilerin dikkate alınması gerektiği söylenebilir.

\section{Teşekkür}

Bu çalışmada değerli katkı ve desteklerinden dolayı Sayın Prof. Dr. Bekir Cihad BAL ve Sayın Dr. Öğr. Üyesi Vedat ÇAVUŞ’a sonsuz teşekkür ederim.

\section{Kaynaklar}

As, N., Koç, H., Doğu, D., Atik, C., Aksu, B., Erdinler, S., (2001), Türkiye'de Yetişen Endüstriyel Öneme Sahip Ağaçların Anatomik, Fiziksel, Mekanik ve Kimyasal Özellikleri. İstanbul Üniversitesi Orman Fakültesi Dergisi. Yayın No: 51 (1): 71-88 
Ayata, Ü., Bal, B., C., Şahin, S., (2019), Akçaağaç (Acer trautvetteri medw.) Odununda 1s1 iletkenlik değeri ve bazı fiziksel özelliklerin belirlenmesi. ISPEC Internatonal conference on Agriculture and rural development-II Proceeding book. 27-29 September 2019, Kiev.

Bal, B. C., (2011), Okaliptïs grandis (Eucalyptus grandis W. Hill ex maiden) odununun fiziksel ve mekanik özellikleri ve lamine ağaç malzeme üretiminde kullanılması üzerine araştırmalar, KSÜ, Fen Bilimleri Enstitüsü, Doktora tezi.

Bal, B. C., Bektaş İ., Kaymakçi, A., (2012), Toros sedirinde genç odun ve olgun odunun bazı fiziksel ve mekanik özellikleri, KSÜ Mühendsilik Bilimleri Dergisi, 15(2), 17-27.

Bal B., C, Bektaș İ, (2018), Odunun yoğunluğu ile bazı mekanik özellikleri arasındaki ilişkinin belirlenmesi üzerine bir araştırma, Mobilya ve Ahşap Malzeme Araştırmaları Dergisi, 1(2), 51-61.

Bektaş, İ. (1997), Kızılçam odununun teknolojik özellikleri ve yörelere göre değişimi, IÜ, Fen Bilimleri Enstitüsü, Doktora Tezi, İstanbul.

Bektaş, İ., Güler, C., and Baştürk, M. A. (2002), Principal mechanical properties of eastern beech wood (Fagus orientalis L.) naturally grown in Andırın northeastern mediterranean region of Turkey, Turk J Agric For, 26(2002), 147-154.

Brand, M., H., (2015). Acer palmatum. University of Connecticut Plant Database. http://www.hort.uconn.edu/plants/detail.php?pid=19.

Bozkurt A., Y., Erdin, N., (2011). Ağaç Teknolojisi Ders Kitabı. İstanbul Üniversitesi Yayın No: 5029 Orman Fakültesi Yayın No: 445 ISBN No: 978-975-404-900-8.

Bozkurt, Y., Erdin, N., (2013), “Odun Anatomisi," İ.Ü. Orman Fakültesi Yayınları, İstanbul, 978-975-404-932-9

Çavuş, V., Ayata, Ü. (2018). Manolya ağacı, akçaağaç ve tespih ağacı odunlarında vida tutma direnci üzerine bir araştırma. Mobilya ve Ahşap Malzeme Araştırmaları Dergisi, 1(2), 94102.

Erten, P. ve Sözen, M. R. 1994. Fıstık Çamı (Pinus pinea), Camiyanı Karaçamı (Pinus nigra Arnold) ve Çınar Yapraklı Akçaagaç (Acer Platonodies) Odununun Bazı Fiziksel ve Mekaniksel Özelliklerinin Belirlenmesi. Doğu Karadeniz Ormancılık Araştırma Enstitüsü Müdürlüğü Teknik Bülten Serisi. 266, 1-37.

Gilman, E., F., (1999). Acer palmatum 'Dissectum'. Fact Sheet FPS-10, Environmental Horticulture Department, Florida Cooperative Extension Service, Institute of Food and Agricultural Sciences, University of Florida. Publication date: October 1999.

Gürgül, S., Uzun, C., Erdal, N., (2016). Kemik Biyomekaniği. Gaziosmanpaşa Üniversitesi Tıp Fakültesi Dergisi 2016;8 (1): 18-34.

Korkut, S., Büyüksarı, Ü., (2006). Some mechanical properties of red-bud maple (Acer trautvetteri Medw.) wood grown in different districts. Düzce Üniversitesi Orman Fakültesi Ormanc1lık Dergisi Cilt 2, Say1 2, $24-31$.

Öner, N., Bilgili, C., B., Çorbacı, Ö., L., (2014). Türkiye'de peyzaj tasarımında kullanılabilecek doğal akçaağaç türlerimizin potansiyel yetişme alanlarının CBS yardımıyla belirlenmesi. III. Uluslararası Odun Dışı Orman Ürünleri Sempozyumu, 8-10 Mayıs 2014, Kahramanmaraş.

Öztürk, S., (2019). Türkiye Akçaağaçları Teşhis ve Tanı Kılavuzu. T. C. Tarım ve Orman Bakanlığı Orman Genel Müdürlüğü Yayınları, Ankara.

TS EN 13446, (2005). Ahşap esaslı levhalar - bağlayıcıların geri çıkma kapasitesinin tayini, Türk Standartları Enstitüsü, Ankara.

TS 2472, (1976). Odunda Fiziksel ve Mekaniksel Deneyler İçin Birim Hacim Ağırlı̆̆ı Tayini, Türk Standartları Enstitüsü, Ankara, 1976. 
TS 2474, (1976). Odunun Statik Eğilme Dayanımının Tayini, Türk Standartları Enstitüsü, Ankara, 1976.

TS 2478, (1976). Odunun Statik Eğilmede Elastiklik Modülünün Tayini, Türk Standartları Enstitüsü, Ankara, 1976.

TS 2477, (1976). Odunun Çarpmada Eğilme Dayanımının Tayini, Türk Standartları Enstitüsü, Ankara, 1976.

Yaltırık, F., (1971a). Researches morphological and anatomical properties of Turkish Acer species, Istanbul University Publication No: 1661, Faculty of Forestry Publication No: 179, 1971a, Istanbul.

Yaltırık, F., (1971b). Site characters and silvicultural aspects of Turkish Acer species, Review of the Faculty of Forestry University of Istanbul, 1971b, Series A, 21(1):81-90, Istanbul. 